\title{
Mengukur Efektivitas Podcast sebagai Media Perkuliahan Inovatif pada Mahasiswa
}

\author{
${ }^{1}$ Farida Rachmawati, ${ }^{2}$ Kurnia Muhajarah, ${ }^{3}$ Naily Kamaliah \\ ${ }^{1,2}$ Dosen Fakultas Dakwah dan Komunikasi, UIN Walisongo Semarang, Indonesia, \\ ${ }^{3}$ Widyaiswara Pusat Pembinaan, Pendidikan dan Pelatihan, LIPI, Bogor, Indonesia \\ ${ }^{1}$ faridarachmawati@walisongo.ac.id, ${ }^{2}$ kurniamuhajarah@walisongo.ac.id, ${ }^{3}$ naily1809@gmail.com
}

\begin{abstract}
ARTICLE INFO
Article History:

Received : 04-03-2019

Revised : 12-05-2019

Accepted : 27-05-2019

Online : 30-05-2019

Keywords:

Efektivitas

Podcast;

Media Perkuliahan

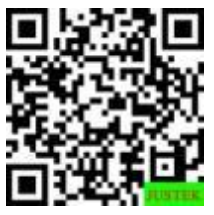

Abstract: Podcasts involve downloading a series of audio or video broadcasts to a digital media player, via smartphone, computer. Podcast is used as a lecture medium by several lecturers at Faculty of Da'wa and Communication, UIN Walisongo Semarang, and its effectiveness as a lecture tool for adults, still needs to be developed. This research is a quantitative type. The purpose of this study was to examine students' perceptions about the effectiveness of using podcasts and conventional revised media. This research was conducted by 127 student respondents. The questionnaire was distributed after students had completed the lecture material and before the Final Semester Examination (UAS) in the Da'wah Methodology course. The questionnaire used a five-point Likert scale to compare their attitudes in revising lecture results on lecturers' lectures, podcasts, notes and lecture modules. The results showed that students perceive podcasts as a revision medium that is more effective than modules and more efficient than their own notes. Students also show that they are more likely to receive lecture material in the form of podcasts than lecturers' lectures or lecture modules. This research shows that using podcasts as a revision medium has clear benefits, particularly in terms of the time they revise and how much they feel they can learn. Podcasts have significant potential as an innovative learning medium for students in Higher Education.
\end{abstract}

Abstrak: Podcast melibatkan pengunduhan serangkaian siaran audio atau video ke pemutar media digital, melalui ponsel pintar, komputer. Podcast digunakan sebagai media perkuliahan oleh beberapa dosen di Fakultas Dakwah dan Komunikasi, UIN Walisongo Semarang, dan keefektifannya sebagai alat perkuliahan untuk orang dewasa, masih harus terus dikembangkan. Penelitian ini berjenis kuantitatif. Tujuan penelitian ini adalah meneliti persepsi mahasiswa tentang efektivitas penggunaan podcast dan media revisi konvensional. Penelitian ini dilakukan oleh 127 responden mahasiswa. Kuesioner dibagikan setelah mahasiswa menyelesaikan materi perkuliahan dan sebelum Ujian Akhir Semester (UAS) pada mata kuliah Metodologi Dakwah. Kuesioner menggunakan skala Likert lima poin untuk membandingkan sikap mereka dalam merevisi hasil perkuliahan terhadap ceramah Dosen, podcast, catatan dan modul kuliah Hasil penelitian menunjukkan bahwa mahasiswa mempersepsi podcast adalah media revisi yang lebih efektif daripada modul dan lebih efisien daripada catatan mereka sendiri. Mahasiswa juga menunjukkan bahwa mereka lebih mudah menerima materi perkuliahan dalam bentuk podcast daripada ceramah Dosen atau modul kuliah. Penelitian ini menunjukkan bahwa penggunaan podcast sebagai media revisi memiliki manfaat yang jelas, terutama hal waktu yang mereka gunakan untuk merevisi dan seberapa banyak mereka merasa dapat belajar. Podcast memiliki potensi signifikan sebagai media perkuliahan inovatif untuk mahasiswa di Perguruan Tinggi. 


\section{A. LATAR BELAKANG}

Podcast merupakan salah satu platform digital populer di dunia. Istilah podcast pertama kali digunakan pada tahun 2000 dan pada tahun 2005 dinyatakan sebagai kata oleh New Oxford American Dictionary (Copley, 2007) Podcast adalah perpaduan antara 'iPod' dan 'broadcasting' (Sheldon, 2017)(Istanto, 2011). Walau penggunaan kata 'pod' dianggap tidak tepat oleh banyak orang, namun kata 'pod' identik dengan iPod dan memposisikan iPod sebagai pengaktif podcasting. Host atau penulis podcast sering disebut podcaster, sedangkan perangkat lunak yang mengelola pengunduhan materi secara otomatis disebut podcatcher. (Jham et al., 2008). Podcast adalah file media yang dapat didistribusikan melalui internet dapat diputar tidak hanya dengan iPod, ponsel pintar, tetapi juga oleh jenis pemutar media lainnya, komputer (misalnya, menggunakan Windows Media Player), sistem stereo atau perangkat audio online seperti Spotify, Joox, Soundcloud.com (Fadilah et al., 2017). Saat gambar video ditransmisikan selain audio, istilah vodcast digunakan (Jham et al., 2008) (Chadha et al., 2012). Pengguna dapat mendengarkan, menonton atau mengunduhnya kapanpun dan dimanapun (Evans, 2008).

Beberapa orang menyebut podcast sebagai radio digital. Berdasarkan data dari Google Trends per 13-19 Desember 2020 di seluruh dunia, popularitas podcast jika dibandingkan vlog adalah 76:9 persen, unggul podcast. Prosentase penggunanyapun, 59:40, sedikit lebih unggul podcast jika dibandingkan dengan vlog (Trends, 2020). Berdasarkan popularitas dan pengunanya tersebut, maka podcast menarik untuk digunakan sebagai inovasi media dalam perkuliahan. Penggunaan podcast sebagai media perkuliahan, telah dilakukan diantaranya oleh (Indriastuti \& Saksono, 2015; Mayangsari \& Tiara, 2019). Podcast sebagai sumber perkuliahan mempunyai beberapa kelebihan, diantaranya reusability dan replaying bahan ajar, kemudahan akses melalui berbagai media putar misalnya MP3 player, MP4 player, handphone, dan memotivasi mahasiswa menggunakan media belajar yang fleksibel (Copley, 2007). Biaya produksi podcast relatif murah, sederhana dan ramah pengguna, Inilah mengapa hampir semua pelanggan podcast gratis (McClung \& Johnson, 2010).

Dalam konteks yang pedagogis, teknologi podcasting semakin banyak digunakan di Perguruan Tinggi. Podcast menawarkan lingkungan belajar yang lebih kaya. Podcast Dosen, yang merupakan rekaman audio dari item seperti ceramah, wawancara, dan bacaan buku (McHugh, 2016) semakin meningkat jumlah penggunanya. Ditambah lagi, keuntungan penggunaan podcast adalah kata-kata yang diucapkan saat podcasting, dapat mempengaruhi kognisi mahasiswa (Hew, 2009) walau pengalaman belajar pasif karena hanya berfokus pada fasilitas audio atau video saja. (McKinney et al., 2009). Dalam konteks ini, perlu ditekankan bahwa podcast harus menjadi pelengkap kuliah. Mahasiswa masih perlu menghadiri kuliah dan menggunakan podcast sambil menulis atau merevisi catatan (Boone, 2007).

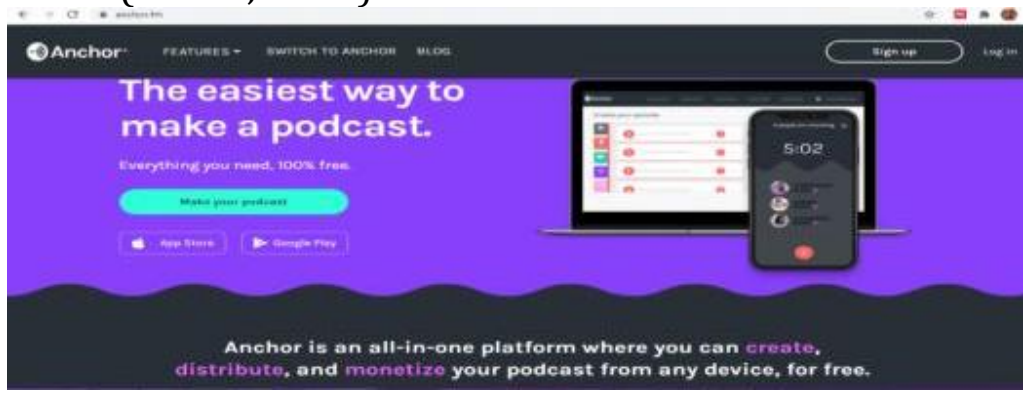

Gambar 1: Tampilan anchor.fm salah satu platform untuk membuat Podcast 
Sumber: https://anchor.fm/

Pengembangan podcast sebagai sumber belajar, juga telah dilakukan oleh Balai Pengembangan Media Radio Dosenan (BPMRP) Kemdikbud dalam portal http://belajar.kemdikbud.go.id dan http://radioedukasi.kemdikbud.go.id. Kriteria kesuksesan podcast audio diantaranya adalah perencanaan dalam menentukan topik yang sesuai. Pegiat podcast mengisi konten mereka sesuai dengan bidang minat dan kemampuan`1nya, juga ketersediaan sumber daya untuk mengerjakan topik-topik yang dipilih. Misalnya, beberapa situs online perguruan tinggi menyediakan materi Podcast berisi topik ilmiah dari para ahli atau pakar yang ada dalam perguruan tinggi tersebut. Selain menentukan topik, menonjolkan kekhasan akun Podcast, juga memperhitungkan potensi khalayak atau pendengar. Podcast dapat memainkan peran sebagai sumber informasi, edukasi, dan hiburan bagi khalayak. Podcast mempunyai potensi besar dengan segmentasi untuk orang dengan kegemaran bertutur, juga kepada pendengarnya dengan karakter auditori (Fadilah et al., 2017)

Mata kuliah Metodologi Dakwah merupakan mata kuliah wajib dan bersifat kefakultasan. Bertujuan membekali mahasiswa dalam mengkaji konsep teoritis berbagai macam metode dakwah serta penerapannya dalam kegiatan dakwah. Peningkatan skill mahasiswa Dakwah, tidak sekadar berbicara tetapi juga bagaimana membangun argumen, membuat script, dan mengemas dengan kreatif, Siaran podcast dalam mata kuliah ini menjadi salah satu aktualisasi metode dakwah bi al-Lisan.

Dalam penelitian ini, peneliti fokus dalam penggunaan podcast sebagai pembanding alat revisi konvensional yang digunakan oleh mahasiswa setelah perkuliahan Metodologi Dakwah selesai, namun sebelum Ujian Akhir Semester (UAS). Penelitian ini bertujuan untuk meneliti persepsi mahasiswa tentang efektivitas penggunaan podcast dan alat revisi konvensional (catatan, modul perkuliahan dan ceramah dosen saat perkuliahan).

\section{B. METODE PENELITIAN}

Penelitian ini berjenis kuantitatif. Responden penelitian ini adalah 127 mahasiswa/i, dengan jumlah 45 mahasiswa dan 82 mahasiswi. Responden ini tersebar di 3 kelas Mata Kuliah Metodologi Dakwah. Semua responden berada pada semester yang sama dan telah memenuhi prasyarat yang sama. Mahasiswa diberi panduan sederhana tentang cara mengakses episode podcast "Walisongo" melalui komputer atau ponsel pintar. Prosedur penelitian ini adalah mahasiswa diberi akses untuk tiga podcast yang dirilis pada interval satu minggu dalam periode revisi setelah perkuliahan selesai tetapi sebelum UAS mereka. Untuk mengakses podcast ketiga, mahasiswa harus mengirimkan jawaban survei online. URL podcast yang tersisa diberikan sebagai umpan balik. Analisis statistik dilakukan dengan memperlakukan data secara non-parametrik, karena, secara tegas, skala Likert memberikan data ordinal daripada data interval. Namun, hasil serupa diperoleh ketika analisis parameter dilakukan.

Hasil observasi peneliti selama perkuliahan berlangsung, membuat peneliti menentukan enam prediksi spesifik untuk memanfaatkan podcast dibandingkan pola revisi konvensional. Ini terkait dengan efisiensi (waktu yang dihabiskan untuk belajar untuk jumlah perkuliahan tertentu), keefektifan (jumlah perkuliahan yang dicapai untuk jumlah materi tertentu), penerimaan mereka (jumlah perkuliahan yang diharapkan untuk jumlah materi tertentu), dan hubungan yang dirasakan mahasiswa dengan dosen saat mendengarkan podcast atau saat ikut perkuliahan. Enam hipotesis eksperimental dirumuskan dalam kategori sebagai berikut: 
H1: Mahasiswa percaya bahwa lebih cepat merevisi dari podcast daripada catatan.

H2: Mahasiswa percaya bahwa merevisi dari podcast lebih efektif daripada catatan

H3: Mahasiswa percaya bahwa merevisi dari podcast lebih efektif daripada modul kuliah

H4: Mahasiswa merasa lebih menerima (reseptif) terhadap materi revisi yang disampaikan dalam bentuk podcast daripada ceramah kuliah dosen

H5: Mahasiswa merasa lebih menerima (reseptif) terhadap materi revisi yang disampaikan dalam bentuk podcast daripada modul kuliah

H6: Mahasiswa merasa bisa lebih berhubungan dengan dosen di podcast daripada ceramah kuliah dosen saat perkuliahan.

Hipotesis pertama, membandingkan podcast dengan catatan daripada modul kuliah, karena dua alasan. Pertama, seperti catatan, waktu yang dipilih mahasiswa untuk belajar dari podcast adalah fleksibel. Mahasiswa bisa menjeda atau mengulanginya sesering yang mereka suka. Kedua, seperti catatan, podcast dirancang untuk meringkas materi dengan cara tertentu. Hipotesis kedua dan ketiga membandingkan podcast dengan catatan dan modul kuliah daripada ceramah kuliah dosen. Alasannya adalah bahwa alat revisi aktual yang tersedia bagi mahasiswa adalah modul kuliah dan ceramah kuliah dosen tidak termasuk dalam penelitian ini.

Hipotesis keempat dan kelima membandingkan podcast dengan modul kuliah dan ceramah kuliah revisi dosen. Alasannya adalah semua ini adalah bentuk alternatif komunikasi langsung antara dosen dan mahasiswa (Namun tidak dengan catatan mahasiswa, karena catatan mahasiswa adalah bentuk komunikasi tidak langsung karena informasi sebagian telah diproses oleh mahasiswa sebelum ditulis). Hipotesis keeenam, mempertimbangkan podcast dan ceramah perkuliahan dosen (bukan catatan mahasiswa atau modul kuliah). Alasannya, keduanya melibatkan unsur komunikasi personal melalui suara (untuk video podcast, gambar) dosen. Bentuk komunikasi ini mencakup isyarat dan intonasi verbal (untuk video, isyarat visual) yang tidak dapat diakses melalui mekanisme lain.

\section{HASIL DAN PEMBAHASAN}

\section{Hasil Penelitian}

Tabel 1: Hasil Kuesioner Peringkat

\begin{tabular}{lllllc}
\hline & $\begin{array}{l}\text { Peringkat } \\
\text { positif }\end{array}$ & $\begin{array}{l}\text { Peringkat } \\
\text { negative }\end{array}$ & Ties & Z & Makna \\
\hline $\begin{array}{l}\text { Podcast cepat - catatan cepat a } \\
\text { Podcast efektif - catatan efektif a }\end{array}$ & 65 & 56 & 54 & 2.934 & $0,002^{*}$ \\
$\begin{array}{l}\text { Podcast efektif - modul kuliah } \\
\text { efektif a }\end{array}$ & 90 & 60 & 73 & 0,553 & 0,291 \\
$\begin{array}{l}\text { Podcast reseptif - } \\
\text { perkuliahan reseptif a }\end{array}$ & 68 & 34 & 63 & 3.924 & $<0,001^{*}$ \\
$\begin{array}{l}\text { Podcast reseptif - modul kuliah } \\
\text { reseptif a }\end{array}$ & 64 & 34 & 94 & 3.592 & $<0,001^{*}$ \\
$\begin{array}{l}\text { Podcast berhubungan - ceramah } \\
\text { dosen berhubungan b }\end{array}$ & 48 & 49 & 98 & 0.812 & 0,417 \\
\hline
\end{tabular}

a Berdasarkan peringkat negatif; ${ }^{b}$ Berdasarkan peringkat positif. * Signifikan pada $\mathrm{p}<.05$. 
Dari 127 mahasiswa, 80\% dari mereka menyatakan bahwa mereka mendengarkan podcast di ponsel, $20 \%$ sisanya mendengarkan di komputer. Hal ini sesuai dengan penelitian (McClung \& Johnson, 2010) dimana 90\% menggunakan ponsel dan 10\% menggunakan komputer mereka.

Statistik deskriptif untuk pertanyaan individu dianalisis secara non-parametrik menggunakan modus bukan mean. Menanggapi pernyataan "Saya pikir penting untuk dapat mendengarkan podcast di mana dan kapanpun saya mau"', tanggapan modus adalah "setuju" (54\%, dengan 25\% lebih lanjut siapa "sangat setuju"). Untuk penyataan '"Saya mendengarkan podcast saat bepergian", modusnya adalah "netral" (34\%, dengan 25\% "setuju" atau "sangat setuju"); dan untuk "Saya mendengarkan podcast sembari melakukan hal lain", modusnya "'tidak setuju" (27\%, dengan $14 \%$ "sangat tidak setuju"). Rentang lengkap skala lima poin digunakan oleh mahasiswa dalam setiap kasus.

Peneliti ingin tahu apakah mahasiswa berpikir bahwa merevisi menggunakan podcast lebih tenang, atau lebih efektif, dan apakah mereka merasa lebih menerima podcast daripada ketika merevisi menggunakan alternatif konvensional. Selain itu kami ingin mengetahui apakah mahasiswa berpikir bahwa mereka dapat berhubungan dengan Dosen lebih baik melalui podcast daripada dalam ceramah. Kami menguji hipotesis ini dengan membandingkan peringkat mahasiswa yang diberikan untuk pasangan pertanyaan yang membedakan podcast dengan salah satu alternatif konvensional.

Tabel 1 menunjukkan jumlah mahasiswa yang memberi peringkat lebih tinggi untuk podcast (peringkat + lima), jumlah yang memberi peringkat lebih rendah (peringkat lima) dan jumlah yang memberi peringkat yang sama (peringkat). Tes peringkat di satu sisi menunjukkan secara signifikan bahwa lebih banyak mahasiswa yang berpikir bahwa merevisi dari podcast lebih cepat dibandingkan dengan merevisi dari catatan. Secara signifikan, lebih banyak mahasiswa yang berpikir bahwa podcast lebih efektif daripada merevisi dari modul. Akhirnya, secara signifikan lebih banyak mahasiswa yang percaya bahwa mereka lebih menerima materi yang disampaikan sebagai podcast daripada modul kuliah atau revisi ceramah kuliah konvensional. Tidak ada perbedaan signifikan yang ditemukan untuk efektivitas podcast dibandingkan dengan merevisi catatan atau kemampuan untuk berhubungan dengan dosen saat mendengarkan podcast dibandingkan dengan kuliah konvensional.

\section{Pembahasan Penelitian}

Hasilnya penelitian menunjukkan bahwa mahasiswa menghargai fleksibilitas yang ditawarkan oleh podcast dalam hal kemampuan untuk belajar kapan dan di mana Anda inginkan. $25 \%$ responden mendengarkan podcast saat bepergian. Bepergian merupakan saat dimana melakukan aktivitas kognitif yang lebih sedikit. Hal ini menunjukkan bahwa podcasting dapat mengisi kesenjangan kebutuhan yang penting dengan memungkinkan mahasiswa untuk melanjutkan kegiatan belajar ketika biasanya tidak memungkinkan. Namun, podcast tampaknya tidak menawarkan banyak cara memfasilitasi multi-tasking, dengan kebanyakan orang mengklaim bahwa mereka tidak melakukan aktivitas lain saat login ke podcast.

Tujuan utama dari penelitian adalah untuk menentukan apakah merevisi melalui podcast meningkatkan proses perkuliahan. Hasilnya memberikan dukungan untuk lima dari enam hipotesis yang menyatakan bahwa mereka melakukannya. Jawaban untuk pasangan pertanyaan pertama pada Tabel 1 menunjukkan bahwa mahasiswa percaya bahwa merevisi dengan podcast adalah cara yang lebih cepat untuk merevisi 
daripada menggunakan catatan mereka sendiri (H1). Podcast adalah siaran mandiri yang langsung melibatkan mahasiswa dengan outcomes dari kuliah tertentu. Sebaliknya, merevisi catatan mengharuskan mahasiswa mengeluarkan energi kognitif untuk membiasakan diri kembali dengan materi dalam konteks di mana mereka pertama kali menemukannya. Kemampuan untuk merevisi tanpa harus mengkontekstualisasikan ulang diri sendiri menawarkan penghematan waktu yang signifikan bagi mahasiswa.

Hasil dari pernyataan (H2) dan (H3) menunjukkan bahwa podcast adalah alat revisi yang lebih efektif daripada modul (H2), tetapi bukan catatan mereka sendiri (H3). Ini berarti bahwa mereka mengklaim bahwa mereka belajar lebih banyak dari podcast daripada membaca bagian yang sesuai dari modul kuliah. Sifat fleksibel dari podcast dapat berarti bahwa lebih mudah bagi mahasiswa untuk terlibat secara aktif dengan materi daripada saat membaca. Fakta bahwa mereka melaporkan bahwa mereka tidak menemukan podcast lebih efektif daripada catatan menunjukkan bahwa format ringkasan podcast memiliki manfaat khusus dalam membantu mahasiswa fokus pada aspek-aspek penting subjek tanpa teralihkan oleh detail.

Hasil dari pernyataan (H4) dan (H5) menunjukkan bahwa mahasiswa lebih reseptif terhadap materi podcast daripada materi yang disampaikan dalam bentuk ceramah dosen (H4) atau dari modul kuliah (H5). Semua ini adalah bentuk komunikasi langsung antara dosen dan mahasiswa. Ini menunjukkan bahwa mahasiswa mungkin merasa lebih terlibat saat mendengarkan podcast. Melalui pemberian kendali yang lebih besar kepada mahasiswa terhadap proses perkuliahan, podcast dapat mendorong pengembangan hubungan yang aktif dengan materi. Sebaliknya, modul kuliah dan ceramah dapat mendorong hubungan pasif di mana mahasiswa mengambil peran sebagai penerima informasi yang sederhana. Sampai saat ini, mungkin, peran utama ceramah dan modul masih dipandang sebagai penyampaian informasi dalam jumlah besar. Sebaliknya, podcast secara khusus dirancang untuk membantu mahasiswa mengasimilasi materi dan membangun pemahaman mereka sendiri (McHugh, 2016).

Hasil dari pertanyaan terakhir (H6) tidak memberikan bukti yang mendukung hipotesis bahwa lebih mudah berhubungan dengan dosen dalam podcast daripada dalam ceramah kuliah. Ini menunjukkan bahwa kuliah sama efektifnya dalam mempersonalisasi materi seperti podcast. Secara keseluruhan, hasil ini memberikan bukti yang baik untuk menunjukkan bahwa mahasiswa berpikir bahwa podcast meningkatkan proses perkuliahan mereka, seperti yang dilaporkan dalam umpan balik mereka (O'Bannon et al., 2011).

Salah satu interpretasi alternatif dari hasil "efektivitas" adalah bahwa itu hanya menunjukkan fakta bahwa podcast tidak bertahan lama (masing-masing berdurasi sekitar 5 menit). Jika ini masalahnya, maka Anda akan berharap data tersebut mencerminkan keyakinan bahwa podcast kurang efektif karena mahasiswa biasanya menghabiskan lebih lama untuk merevisi catatan mereka. Namun, jawaban atas pertanyaan tentang efektivitas tidak menunjukkan bukti bahwa mereka menganggap podcast kurang efektif. Ini menunjukkan bahwa interpretasi yang lebih baik adalah mereka menemukan podcast sebagai alat revisi yang lebih efisien. Penelitian selanjutnya akan melibatkan kuesioner yang menggambarkan efisiensi sebagai lawan durasi, mungkin dengan membuat mahasiswa mempertimbangkan periode waktu yang sama untuk masing-masing studi. Mereka juga harus mengukur berapa kali mahasiswa melakukan mendengarkan podcast berulang kali dalam upaya untuk mengukur total waktu mendengarkan. 


\section{TEMUAN PENELITIAN}

Penjelasan alternatif bahwa podcast lebih efektif daripada modul kuliah adalah karena podcast diarahkan untuk mengasimilasi dan menyajikan kembali konten mata kuliah (yaitu merevisi). Ini akan menjelaskan mengapa tidak ada bukti bahwa podcast lebih efektif daripada merevisi dari catatan. Dalam kombinasi bahwa mahasiswa lebih menerima materi dalam podcast daripada ceramah dosen, akan tampak bahwa mahasiswa merasa lebih terlibat dan ini mungkin penjelasan yang lebih baik mengapa mereka percaya bahwa mereka lebih efektif untuk revisi.

Hasil penelitian menunjukkan bahwa mahasiswa menemukan podcast sebagai alat perkuliahan yang efisien, efektif, menarik dan mudah diterima untuk revisi (McKinney et al., 2009). Podcast membantu mahasiswa mereka terlibat dengan materi. Ini juga mendukung peningkatan peringkat kepuasan mahasiswa terhadap penggunaan podcast (Merhi, 2015). Periode revisi biasanya merupakan saat stres tinggi bagi mahasiswa sebelum ujian mereka. Hasilnya juga memperkuat gagasan bahwa podcast berkontribusi pada pengurangan kecemasan mahasiswa seperti yang ditemukan oleh Chan dan Lee, 2005 (Laningham, 2006). Penggunaan podcast saat bepergian membuatnya lebih mudah diakses daripada beberapa alternatif konvensional. Artinya, mereka dapat mengakomodasi praktik perkuliahan yang lebih luas. Podcast membuat materi dapat diakses oleh lebih banyak mahasiswa.(O’Bannon et al., 2011)(Merhi, 2015).

\section{E. SIMPULAN DAN SARAN}

Simpulan dari penelitian ini adalah hasil penelitian menunjukkan bahwa mahasiswa percaya podcast adalah alat revisi yang lebih efektif daripada modul dan lebih efisien daripada catatan mereka sendiri dalam membantu mereka belajar. Mahasiswa juga menunjukkan bahwa mereka lebih mudah menerima materi perkuliahan dalam bentuk podcast daripada ceramah dosen saat perkulaiahan atau modul buku. Penelitian ini menunjukkan bahwa penggunaan podcast sebagai alat revisi memiliki manfaat yang jelas seperti yang dirasakan oleh mahasiswa dalam hal waktu yang mereka gunakan untuk merevisi dan seberapa banyak mereka merasa dapat belajar. Hal ini juga diperkuat dengan keuntungan fleksibilitas kapan, di mana, dan bagaimana podcast digunakan. Podcast tampaknya memiliki potensi signifikan sebagai alat perkuliahan inovatif untuk mahasiswa dewasa di Perguruan Tinggi.

Saran peneliti untuk penelitian selanjutnya adalah melibatkan kuesioner yang menggambarkan efisiensi sebagai lawan durasi, mungkin dengan membuat mahasiswa mempertimbangkan periode waktu yang sama untuk masing-masing alat sebagai upaya mengukur total waktu mendengarkan.

\section{REFERENSI}

Chadha, M., Avila, A., \& Gil de Zúñiga, H. (2012). Listening In: Building a Profile of Podcast Users and Analyzing Their Political Participation. Journal of Information Technology and Politics. https://doi.org/10.1080/19331681.2012.717481

Boone J. Podcasts allow students to listen and learn at leisure. At: www.ft.com/cms/s/0/b71f22-aa2-11da8b6-000077e20.html?nclick_check=1.

Copley, J. (2007). Audio and video podcasts of lectures for campus-based students: Production and evaluation of student use. Innovations in Education and Teaching International. https://doi.org/10.1080/14703290701602805

Evans, C. (2008). The effectiveness of m-learning in the form of podcast revision lectures in higher education. Computers and Education. 
https://doi.org/10.1016/j.compedu.2007.09.016

Fadilah, E., Yudhapramesti, P., \& Aristi, N. (2017). Podcast sebagai Alternatif Distribusi Konten Audio. Jurnal Kajian Jurnalisme. https://doi.org/10.24198/kj.v1i1.10562

Hew, K. F. (2009). Use of audio podcast in K-12 and higher education: A review of research topics and methodologies. Educational Technology Research and Development. https://doi.org/10.1007/s11423-008-9108-3

Indriastuti, F., \& Saksono, W. T. (2015). Podcast Sebagai Sumber Belajar Berbasis Audio Audio Podcasts As Audio-Based Learning Resources. Jurnal Teknodik, 18(1), 304314.

Istanto, Johanna Wulansari \& Indrianti. (2011). Pelangi Bahasa Indonesia Podcast: What, Why and How? Electronic Journal of Foreign Language Teaching, 8 (1), pp. 371-384

Jham, B. C., Duraes, G. V., Strassler, H. E., \& Sensi, L. G. (2008). Joining the Podcast Revolution. Journal of Dental Education. https://doi.org/10.1002/j.00220337.2008.72.3.tb04493.x

Laningham, S. (2006). developerWorks Interviews: Tim Berners-Lee. IBM DeveloperWorks.

Mayangsari, D., \& Tiara, D. R. (2019). Podcast Sebagai Media Pembelajaran Di Era $\begin{array}{llll}\text { Milenial. Jurnal Golden } & \text { Age, }\end{array}$ https://doi.org/10.29408/goldenage.v3i02.1720

McClung, S., \& Johnson, K. (2010). Examining the motives of podcast users. Journal of Radio and Audio Media. https://doi.org/10.1080/19376521003719391

McHugh, S. (2016). How podcasting is changing the audio storytelling genre. Radio Journal. https://doi.org/10.1386/rjao.14.1.65_1

McKinney, D., Dyck, J. L., \& Luber, E. S. (2009). iTunes University and the classroom: Can podcasts replace Professors? Computers and Education. https://doi.org/10.1016/j.compedu.2008.11.004

Merhi, M. I. (2015). Factors influencing higher education students to adopt podcast: An empirical study. Computers and Education. https://doi.org/10.1016/j.compedu.2014.12.014

O'Bannon, B. W., Lubke, J. K., Beard, J. L., \& Britt, V. G. (2011). Using podcasts to replace lecture: Effects on student achievement. Computers and Education. https://doi.org/10.1016/j.compedu.2011.04.001

Sheldon, M. P. (2017). Podcast. Science (New York, N.Y.). https://doi.org/10.1126/science.aam7391

Trends, G. (n.d.). podcast, vlog, video blog - Explore - Google Trends. 